\title{
Survival of COVID-19 Patients Who Received Antiviral and Antiviral Therapy Combined with Anti-inflammation Therapy in a National Referral Hospital, Indonesia
}

\author{
Afriani Afriani ${ }^{1 *}$ D , Sabrina Ermayanti ${ }^{2}$ D, Irvan Medison $^{1}$, Russilawati Russilawati ${ }^{2}$, Fenty Anggrainy ${ }^{2}$, Yessy Susanty Sabri ${ }^{2}$, \\ Ricvan Dana Nindrea ${ }^{3}$ D \\ ${ }^{1}$ Department of Pulmonology and Respiratory Medicine, Dr. M Djamil General Hospital, Padang, Indonesia; ${ }^{2}$ Department \\ of Pulmonology and Respiratory Medicine, Faculty of Medicine, Universitas Andalas, Padang, Indonesia; ${ }^{3}$ Department of \\ Education and Research, Dr. M Djamil General Hospital, Padang, Indonesia
}

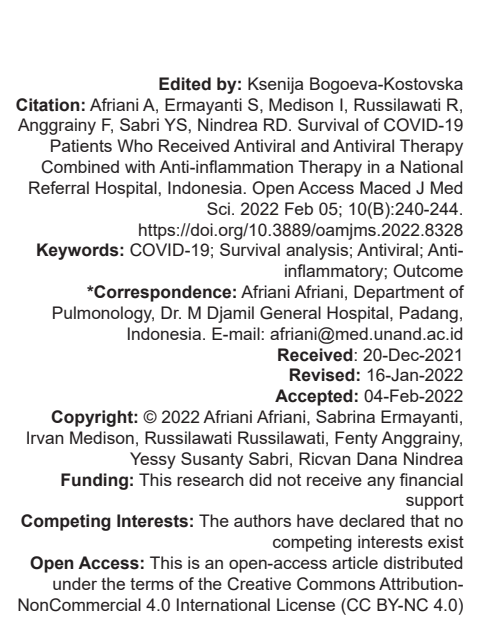

\section{Introduction}

COVID-19 infections have been reported in 213 countries and territories outside of mainland China [1]. COVID-19 infection has had a considerable impact in the United States, Europe, and Asia. COVID-19 had infected over 109.21 million individuals globally and killed over 2.4 million people as of February 2021 [2]. The number of cases among people aged 65 and up is extremely significant. There is no discernible distinction between males and women. Incubation lasts an average of 5.2 days. In a Wuhan study of 85 severe COVID-19 patients with a median age of 65 years, the majority of patients died from multiorgan failure, including respiratory failure (94\%), shock (81\%), and acute respiratory distress syndrome (ARDS) (74\%), which are consistent with the high prevalence of multiorgan failure, high levels of d-dimer, fibrinogen, and prolonged thrombin time [3].
The majority of modern medical care is not standardized. Several medicines have been investigated in clinical trials, including lopinavir-ritonavir, remdesivir, hydroxychloroquine, and azithromycin, but none have yet been proven to be effective [4]. Finding medications to control and treat COVID-19 infection are difficult. Several prospective medications are now being utilized at various stages of the illness, but no therapy has yet been demonstrated to be completely successful. Colchicine, a chemical often used to treat gout and several autoinflammatory diseases such as adult onset illness, Behçet's disease, Mediterranean fever, and cardiac issues, is one medicine that might be useful [5].

Colchicine has been used for more than a decade to treat the symptoms of iatrogenic allogenosis (IA), a condition caused by allogeneic chemicals that enter the body, such as modeling agents or foreign biopolymers. Colchicine lowers arthralgia, headaches, and lung infiltrates, as well as other inflammatory symptoms and clinical presentations. The 
patients' clinical condition improved and the frequency of their complaints decreased [6].

The tricyclic alkaloid colchicine is derived from the colchicum autumnale plant. Colchicine is a potent tubulin polymerization inhibitor. The high affinity of colchicine for attaching to the tubulin subunit, which prevents it from accumulating and so preventing microtubule polymerization, is the most researched mechanism. Microtubules are a component of the cytoskeleton that play a role in a variety of cellular functions, including cell shape maintenance, intracellular substance transfer, cytokine and chemokine secretion, cell migration, ion channel regulation, and cell division. Colchicine also affects the chemotaxis of inflammatory cells such as neutrophils and monocytes, as well as intracellular vesicle movement such as endosomes and exosomes. Colchicine also reduces the production of E-selectin, an adhesion molecule required for leukocyte adherence to endothelial cells and monocyte and neutrophil recruitment to inflamed tissues. Finally, colchicine inhibits the generation of neutrophils by free radicals such as superoxide. After that, inflammasome activity is inhibited, preventing caspase- 1 activation and the production of IL-1 and IL-18 [7].

SARS-CoV-1 infection has been linked to calcium ion transport activation, which results in IL-1 overproduction, direct caspase-1 activation, or increased potassium excretion. Colchicine is $40 \%$ bound to albumin in the circulation. Based on intraleukocyte accumulation, peak concentrations occur $1 \mathrm{~h}$ after injection and the greatest anti-inflammatory impact develops over 24-48 h. Colchicine reaches substantially larger amounts in leukocytes than it does in plasma, and it stays there for days after intake [8], [9].

Several studies have recently suggested that cytokine release syndrome (CRS) may affect a subset of individuals with severe COVID-19. CRS is a potentially fatal toxicity characterized by a rise in tumor necrosis factor (TNF), followed by increases in interleukin (IL)-1, IL-2, IL-6, IL-8, IL-10, and interferon- $\gamma$ (IFN- $\gamma$ ). IL-2, IL-7, IFN, granulocyte colony-stimulating factor, monocyte chemoattractant protein 1, macrophage inflammatory protein 1, and TNF were all shown to be high in COVID-19 and IL-6 was used as a predictor of death. All provided findings may be regarded evidence, demonstrating the inflammatory process' activation and the incidence of CRS in COVID-19-positive critically sick patients [10]

Colchicine may be a potential therapy option in the battle against the COVID-19-induced cytokine storm, according to the Papadopoulus et al. It is a more appealing alternative due to its relatively inexpensive cost and ample availability. However, due of the risk of drug-drug interactions (DDI), vigilance should be maintained. Early reports on effectiveness are promising, but there is still a lot of work to be done. A study including 105 individuals who were randomly assigned to receive either regular therapy or normal treatment with colchicine [10].

\section{Methods}

\section{Study design and research samples}

This is a retrospective cohort research with an analytical study. All COVID-19 patients treated in the COVID-19 isolation room at Dr M Djamil Hospital Padang from January to December 2021 were included in this research. The patients above the age of 18 were eligible for the study, as were COVID-19 patients taking antiviral and antiviral medication, as well as antiinflammatory medicines. Incomplete medical record data are an exclusion criterion.

\section{Operational definitions}

Antiviral and antiviral and anti-inflammatory medication was the independent factors in severe and critical clinical COVID-19 patients. In this study, the antiviral in question is remdesivir. Colchicine is the antiinflammatory drug mentioned in this study. The analysis of COVID-19 patients' survival is the dependent variable.

\section{Research procedure}

Theresearchersstarted bygatheringinformation from the medical records of COVID-19 patients who got antiviral medication together with anti-inflammatory medicines (Group A), which included 81 subjects, and antiviral therapy only (Group B), which included 83 subjects.

\section{Data analysis}

Computerized data processing and statistical analysis were carried out. The independent sample $T$ test and the Chi-square test were used to examine the subject's characteristics. Furthermore, Kaplan-Meier survival analysis was used to calculate the median survival and survival rate for the study hypothesis. If $p<0.05$ is significant and the hazard ratio $(\mathrm{HR})$ is known, the following study will use cox-regression to answer the research hypothesis, with the interpretation that $H R>1$ is a risk factor and HR 1 is a preventative factor. SPSS version 18.0 was used to analyze the data.

\section{Results}

Subject characteristics (Table 1).

Table 1 showed in COVID-19 patients receiving antiviral and antiviral treatment with anti-inflammatories, there are variations in concomitant hypertension, diabetes mellitus, and chronic kidney disease, as well as outcomes $(p<0.05)$. 
Table 1: Subject characteristics

\begin{tabular}{|c|c|c|c|c|}
\hline \multirow[t]{2}{*}{ Variables } & \multicolumn{2}{|l|}{ Therapy } & \multirow[t]{2}{*}{$\mathrm{p}$-value } & \multirow[t]{2}{*}{$\mathrm{HR}(95 \% \mathrm{Cl})$} \\
\hline & Group A (n = 81) & Group B $(n=83)$ & & \\
\hline Age, mean $\pm S D$ & $60.95 \pm 12.11$ & $56.72 \pm 17.80$ & $0.077^{\mathrm{a}}$ & $2.37(0.46-8.92)$ \\
\hline Sex, $f(\%)$ & & & $0.339^{b}$ & \\
\hline Male & $48(59.3)$ & $42(50.6)$ & & $1.42(0.77-2.63)$ \\
\hline Female & $33(40.7)$ & $41(49.4)$ & & Ref \\
\hline \multicolumn{5}{|l|}{ Comorbidity, f (\%) } \\
\hline Hypertension & $13(16.0)$ & $1(1.2)$ & $0.002^{b_{*}}$ & $15.68(2.00-122.89)$ \\
\hline Diabetes mellitus & $19(23.5)$ & $6(7.2)$ & $0.008^{\mathrm{b}}$ & $3.93(1.48-10.45)$ \\
\hline Overweight & $2(2.5)$ & 0 & $n / a^{b}$ & $\mathrm{n} / \mathrm{a}$ \\
\hline Chronic kidney disease & $11(13.6)$ & $1(1.2)$ & $0.006^{b_{*}}$ & $12.89(1.62-102.30)$ \\
\hline Heart disease & $2(2.5)$ & 0 & $n / a^{b}$ & $\mathrm{n} / \mathrm{a}$ \\
\hline Outcome, f (\%) & & & $<0.001^{b *}$ & \\
\hline Death & $74(91.4)$ & $47(56.6)$ & & $8.09(3.33-19.69)$ \\
\hline Life & $7(8.6)$ & $36(43.4)$ & & Ref \\
\hline Length of stay (hari), mean $\pm S D$ & $9.31 \pm 6.21$ & $8.29 \pm 6.59$ & $0.310^{\mathrm{a}}$ & $1.02(0.99-2.99)$ \\
\hline
\end{tabular}

The impact of antiviral, antiviral, and antiinflammatory medication on COVID-19 patients' length of stay (Table 2).

Table 2: The impact of antiviral, antiviral, and anti-inflammatory medication on COVID-19 patients' length of stay

\begin{tabular}{lllll}
\hline Length of stay & Therapy & p-value & HR $(95 \% \mathrm{Cl})$ \\
\cline { 2 - 3 } & Group $\mathrm{A}(\mathrm{n}=81)$ & Group B $(\mathrm{n}=83)$ & & \\
\hline$>21$ days & $3(3.7)$ & $3(3.6)$ & $1.000^{\mathrm{b}}$ & $1.03(0.20-5.24)$ \\
$\leq 21$ days & $78(96.3)$ & $80(96.4)$ & & Ref \\
\hline${ }^{\mathrm{b}}$ Chi-square test; ${ }^{*} \mathrm{p}<0.05$ considered significant; Group A: Antiviral and anti-inflammatory therapy;
\end{tabular}

${ }^{\circ}$ Chi-square test; ${ }^{*} p<0.05$ considered significant; Group A: Antiviral and anti-inflammatory therapy;

Group B: Antiviral therapy; HR: Hazard ratio; Ref: Reference.

Table 2 reveals that antiviral and antiviral medication, as well as anti-inflammation, had no effect on the length of stay of COVID-19 patients ( $p>0.05)$.

The role of antiviral, antiviral, and antiinflammatory medication in COVID-19 patients' outcomes (Table 3 and Figure 1).

Table 3: The role of antiviral, antiviral, and anti-inflammatory medication in COVID-19 patients' outcomes

\begin{tabular}{lllll}
\hline Outcome & Rate $(\%)$ & Median follow-up (day) $(95 \% \mathrm{Cl})$ & $\mathrm{p}$-value & $\mathrm{HR}(95 \% \mathrm{Cl})$ \\
\hline Group A & 91.4 & $9.00(7.33-10.67)$ & $0.046^{*}$ & $0.69(0.48-0.99)$ \\
Group B & 56.6 & $11.00(3.02-18.98)$ & & \\
\hline${ }^{*} \mathrm{p}<0.05$ considered significant; Group A: Antiviral and anti-inflammatory therapy; Group B: Antiviral
\end{tabular}
therapy; HR: Hazard ratio.

Table 3 shows that patients receiving antiviral and anti-inflammatory medication had a greater death rate $(91.4 \%)$ than those receiving antiviral therapy $(56.6 \%)$. Individuals receiving antiviral and anti-inflammatory medication had a shorter median follow-up length of stay, 9 days, compared to patients receiving antiviral therapy, which was 11 days. According to the results of statistical test analysis, there is a significant relationship between antiviral and antiviral therapy, as well as antiinflammation, and the outcome of COVID-19 patients ( $p$ 0.05), where patients who receive antiviral and antiinflammatory therapy have a lower final outcome than patients who do not, $\mathrm{HR}=0.69(95 \% \mathrm{Cl} 0.48-0.99)$.

\section{Discussion}

According to the findings, antiviral and antiviral medication had no effect on the duration of stay of
COVID-19 patients $(p>0.05)$. When the length of stay of patients on antiviral therapy was compared to the length of stay of patients on antivirals and anti-inflammatories, the results revealed that the longest length of stay was 21 days, with $80(96.4 \%)$ in antiviral therapy subjects and $78(96.3 \%)$ in antiviral therapy and anti-inflammatory therapy subjects. COVID-19 patients taking colchicine had a faster time to clinical improvement, according to the research by Deftereos et al. [11]. The use of colchicine reduced the time spent on supplementary oxygen treatment and hospitalization [12]

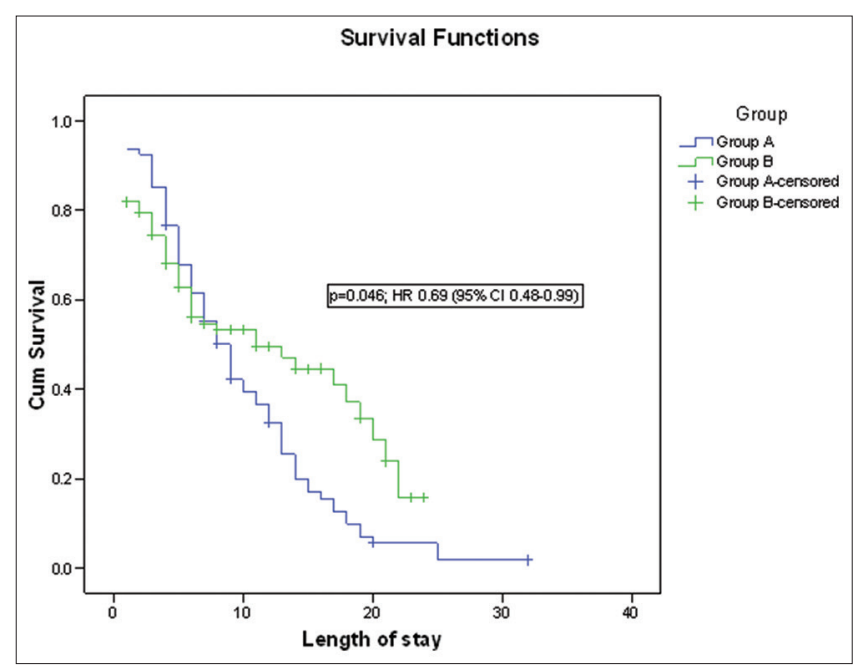

Figure 1: The role of antiviral, antiviral, and anti-inflammatory medication in COVID-19 patients' outcomes

At 21 days of the treatment, COVID-19 patients who received colchicine showed a higher survival rate than those who received conventional therapy $(84.2 \%$ vs. $63.6 \%, p=0.001)$ [13]. Colchicine is predicted to reduce the patient's auto-inflammatory response when given at the start of the COVID-19 phase [13]. Meanwhile, the previous study found that the death rate in COVID-19 patients was lower in the colchicine group than in the usual treatment group (OR 0.2, 95\% Cl, 0.05-0.80; $p=0.023$ ). The patients on colchicine were 5 times more likely to be outpatient at the conclusion of the study $(p=0.023)$ than those on conventional treatment [14].

The patients who received colchicine used less oxygen and were more likely to be discharged 
on day 10. Colchicine dramatically improved tissue oxygenation $\left(\mathrm{PaO}_{2} / \mathrm{FiO}_{2}\right)$ and decreased lung inflammation. The rate of serious problems was observed to be lower in COVID-19 patients who were given colchicine than in those who were given a placebo [15], [16].

According to the findings, the patients receiving antiviral and anti-inflammatory medication had a greater death rate $(91.4 \%)$ than individuals receiving antiviral therapy $(56.6 \%)$. Individuals receiving antiviral and anti-inflammatory medication had a shorter median follow-up length of stay, 9 days, compared to patients receiving antiviral therapy, which was 11 days. According to the results of statistical test analysis, there is a significant relationship between antiviral and antiviral therapy, as well as anti-inflammation, and the final outcome of COVID-19 patients $(p<0.05)$, where the patients who receive antiviral and anti-inflammatory therapy have a lower outcome than patients who do not, $\mathrm{HR}=0.69$ for antiviral (95\% Cl 0.48-0.99).

A prior research compared standard medication (hydroxychloroquine and/or dexamethasone iv, and/ or lopinavir/ritonavir) with the addition of colchicine $1 \mathrm{mg} /$ day to normal therapy in instances of COVID-19 with pneumonia and ARDS and showed the patients who received colchicine lived longer. Compared to normal care, there was superior healing $(84.2 \%$ vs. $63.6 \%$, $p=0.001)$ and a decreased death rate $(p<0.0001)$. Death is associated with advanced age, low $\mathrm{PaO}_{2} / \mathrm{FiO}_{2}$, and high ferritin levels at the time of admission to the hospital [15].

Another research comparing the effects of colchicine $0.5 \mathrm{mg}$ twice daily for 3 days followed by once daily for 30 days on outpatients with COVID-19 found that the patients receiving colchicine had greater mortality, length of stay, and lower hospital rates than placebo [16].

\section{Conclusion}

In comparison to patients getting antiviral medication only, this study demonstrates that the patients receiving antiviral and anti-inflammatory therapy are a preventative factor in the patient's final prognosis. Based on additional factors that contribute to COVID-19 patients' poor results, more study is needed to look at the influence of antiviral and antiviral as well as anti-inflammatory medication on the final outcome of COVID-19 patients.

\section{References}

1. Majumder J, Minko T. Recent developments on therapeutic and diagnostic approaches for COVID-19. AAPS J. 2021;23(1):14. https://doi.org/10.1208/s12248-020-00532-2

PMid:33400058

2. Tsatsakis A, Calina D, Falzone L, Petrakis D, Mitrut R, Siokas V, et al. COVID-19pathophysiology and its clinical implications: An integrative overview of the pharmacotherapeutic management of COVID-19. Food Chem Toxicol. 2020;146:111769. https://doi. org/10.1016/j.fct.2020.111769

PMid:32979398

3. Varghese PM, Tsolaki AG, Yasmin H, ShastriA, Ferluga J, Vatish M, et al. Host-pathogen interaction in COVID-19: Pathogenesis, potential therapeutics and vaccination strategies. Immunobiology. 2020;225(6):152008. https://doi.org/10.1016/j.imbio.2020.152008 PMid:33130519

4. Dhama K, Khan S, Tiwari R, Sircar S, Bhat S, Malik YS, et al. Coronavirus disease 2019-COVID-19. Clin Microbiol Rev. 2020;33(4):e00028-20. https://doi.org/10.1128/CMR.00028-20 PMid:32580969

5. WHO Coronavirus Disease (COVID-19) Dashboard. Geneva: WHO. Accessed from: https://www.covid19.who.int/table [Last accessed 2021 Dec 10].

6. Cao YC, Deng QX, Dai SX. Remdesivir for severe acute respiratory syndrome coronavirus 2 causing COVID-19: An evaluation of the evidence. Travel Med Infect Dis. 2020;35:101647. https://doi.org/10.1016/j.tmaid.2020.101647 PMid:32247927

7. Zhang J, Wang M, Zhao M, Guo S, Xu Y, Ye J, et al. The clinical characteristics and prognosis factors of mild-moderate patients with COVID-19 in a mobile cabin hospital: A retrospective, single-center study. Front Public Health. 2020;8:264. https://doi. org/10.3389/fpubh.2020.0026

PMid:32582615

8. Grein J, Ohmagari N, Shin D, Diaz G, Asperges E, Castagna A, et al. Compassionate use of remdesivir for patients with severe Covid-19. N Engl J Med. 2020;382(24):2327-36. https://doi. org/10.1056/NEJMoa2007016

PMid:32275812

9. Chugh H, Awasthi A, Agarwal Y, Gaur RK, Dhawan G, Chandra R. A comprehensive review on potential therapeutics interventions for COVID-19. Eur J Pharmacol. 2021;890:173741. https://doi. org/10.1016/j.ejphar.2020.173741 PMid:33227287

10. Yuki K, Fujiogi M, Koutsogiannaki S. COVID-19 pathophysiology: A review. Clin Immunol. 2020;215:108427. https://doi. org/10.1016/j.clim.2020.108427 PMid:32325252

11. Deftereos SG, Giannopoulos G, Vrachatis DA, Siasos GD, Giotaki SG, Gargalianos P, et al. Effect of colchicine vs standard care on cardiac and inflammatory biomarkers and clinical outcomes in patients hospitalized with Coronavirus disease 2019: The GRECCO-19 randomized clinical trial. JAMA Netw Open. 2020;3(6):2013136. https://doi.org/10.1001/ jamanetworkopen.2020.13136 PMid:32579195

12. Lopes MI, Bonjorno LP, Giannini MC, Amaral NB, Menezes PI, Dib SM, et al. Beneficial effects of colchicine for moderate to severe COVID-19: A randomised, double-blinded, placebocontrolled clinical trial. RMD Open. 2021;7(1):e001455. https:// doi.org/10.1136/rmdopen-2020-001455 
PMid:33542047

13. Scarsi M, Piantoni S, Colombo E, Airó P, Richini D, Miclini M, et al Association between treatment with colchicine and improved survival in a single-centre cohort of adult hospitalised patients with COVID19 pneumonia and acute respiratory distress syndrome. Ann Rheum Dis. 2020;79(10):1286-9. https://doi. org/10.1136/annrheumdis-2020-217712

PMid:32732245

14. Brunetti L, Diawara O, Tsai A, Firestein BL, Nahass RG, Poiani G, et al. Colchicine to weather the cytokine storm in hospitalized patients with COVID-19. J Clin Med. 2020;9(9):2961. https://doi. org/10.3390/jcm9092961
PMid:32937800

15. Mehta KG, Patel T, Chavda PD, Patel P. Efficacy and safety of colchicine in COVID-19: A meta-analysis of randomised controlled trials. RMD Open. 2021;7(3):e001746. https://doi. org/10.1136/rmdopen-2021-001746

PMid:34810227

16. Golpour M, Mousavi T, Alimohammadi M, Mosayebian A, Shiran $M$, Navaei RA, et al. The effectiveness of Colchicine as an antiinflammatory drug in the treatment of Coronavirus disease 2019: Meta-analysis. Int J Immunopathol Pharmacol. 2021;35:1-8. https://doi.org/10.1177/20587384211031763

PMid:34250834 